\title{
Young people's contraception and sexual health: Report of a local needs assessment in Staveley, North Derbyshire
}

\author{
Amanda Smith, MBBS, MRCGP, DRCOG, DFFP, Clinical Medical Officer
}

Correspondence: Amanda Smith, Contraception and Sexual Health Services, Community Health Care Service (North Derbyshire) NHS Trust, Saltergate Health Centre, Chesterfield, North Derbyshire, S40 1SX, UK.

(Accepted July $\left.13^{\text {th }}, 2000\right)$

\begin{abstract}
Summary
This project assessed the contraception and sexual health needs of people aged under 25 years in the small town of Staveley, UK, and sought to determine how the community family planning service could best meet these needs. One hundred and seventeen young people and 17 local professionals took part. The preferred ideal was found to be a holistic youth service based in an accessible, non-clinic setting. Clinic-based services should be more user-friendly, and various ways to achieve this were suggested. Both clients and professionals need greater awareness of all local services.
\end{abstract}

\section{Key words}

contraception, needs assessment, sexual health, teenagers, young people

\section{Key message points}

- Qualitative and quantitative methods were required to give a detailed assessment of local needs.

- The preferred ideal would be a holistic youth service in a non-clinic based setting.

- More young people would be inclined to use existing clinic based services if they were modified to be more 'user friendly'.

- Awareness of all local services by young people and professionals needs to be improved.

\section{Introduction}

Staveley is a small town with high social deprivation surrounded by ex-mining villages. Declining attendance figures prompted the need for a review of the Saturday morning community family planning clinic (FPC).

This project aimed to assess the contraception and sexual health needs of people under 25 years of age (users and potential users), and to identify how the community family planing service could be tailored to respond to their needs. (The views of the relatively older population currently using the service were identified in a separate survey).

\section{Method}

Epidemiological data including fertility, abortion, and conception rates were reviewed in an attempt to determine local contraceptive service performance indicators. ${ }^{1}$

Young people, recruited by school personal and social education (PSE) co-ordinators, youth workers and family planning service staff, completed an anonymous structured questionnaire.

Six young men and seven young women participated in two mixed focus groups and two individual interviews. Participatory methods based on questions ${ }^{2}$ that were used in a previous teenage sexual health needs assessment ${ }^{3}$ were employed.

Seventeen key local professionals were interviewed using a semi-structured questionnaire.

\section{Results}

The epidemiological data available were not recorded in enough detail to determine the effectiveness of existing local services. The questionnaire and qualitative information enabled a picture of the issues facing local young people and possible solutions to be identified.

Study population

One hundred and seventeen young people took part in the study (Table 1).

Table 1 Age and gender of questionnaire responders

\begin{tabular}{lcccr}
\hline & $\begin{array}{c}13-15 \\
\text { Years }\end{array}$ & $\begin{array}{c}16-24 \\
\text { Years }\end{array}$ & $\begin{array}{c}\text { Age not } \\
\text { specified }\end{array}$ & Total \\
\hline Female & 29 & 38 & 1 & 68 \\
Male & 18 & 27 & & 45 \\
Total & 47 & 65 & & 113 \\
Spoilt questionnaires & & & & 4 \\
\hline
\end{tabular}

Characteristics of the ideal service

The service must offer all contraceptive methods, emergency contraception, pregnancy testing, termination of pregnancy counselling, information and advice about sexually transmitted infections (STI), safer sex, relationship problems, sexual difficulties and menstrual problems. Cervical cytology, preconception and early pregnancy counselling must also be available.

The ideal would be a comprehensive service also offering advice on other health related issues, including acne, smoking, drugs, alcohol and child abuse, plus social issues, including housing and benefits. A counselling service is likely to be well used. All facilities should ideally be available at the same venue.

Professionals felt that enough local services were already available. More questionnaire responders felt they would prefer to use a FPC (48\%) or a young people's clinic (46\%) than a general practitioner (GP) (15\%). Only $4 \%$ of under 16 year olds felt they would prefer to use the GP. Focus group participants felt that if current services were modified to meet their needs then more would use them.

Young people need to be constantly reassured that consultations are confidential in all services. They need to be able to 'walk in' and be seen, without an appointment, and sessions need to be separate from those for older people. The environment should be relaxed and informal. Comfortable seating, appropriate posters, magazines, music, television or video and drinks machines in the waiting room can help.

\section{Receptionist issues}

A receptionist, if necessary, should take the client's first name only. In services where clients have to ask for an urgent appointment in order to be seen the same day, this 
should be arranged without questions being asked as to the reason for the urgency. The receptionist should be in a private room, separate from the waiting room, so that users do not have to give personal details, or ask for supplies, over a counter or through a window.

\section{Staff characteristics}

A female member of staff is required. Having a male staff member may encourage those young men who prefer to see a male (15.6\% of male questionnaire responders) to use the service. Staff must be friendly, caring, non-judgmental and committed to working with young people.

\section{Service location}

Services need to be located in Staveley and in a large local village. The building needs to be easy to access, but not in the middle of the busy town centre. Improved access for one particularly isolated village is needed. One possible model would be a mobile service.

\section{Opening times}

Services should be open more than once a week, ideally every day. Times should include Saturday mornings. Altering the timing to cover lunchtime will increase accessibility for young people. Other popular times include Saturday afternoons, Sunday lunch time and afternoons, Friday afternoons, Wednesdays, and Monday mornings. Local services could liase to ensure the whole week is covered, with a spread of times of day, for facilities such as emergency contraception.

\section{Awareness of local services}

Although knowledge of the FPC was good amongst Staveley residents, awareness of other local services, and awareness of the FPC amongst surrounding villagers, was poor. Existing services need to be more widely publicised.

Advertising by posters and newspaper flyers has previously been associated with an increase in numbers attending Staveley FPC. A consistent approach is required. Locals should be involved in choosing the layout of posters and leaflets, with reference to previously published guidelines. 4

Good places to advertise include schools and colleges, youth clubs, shops, pubs and clubs, and buses. Other suggestions included community centre notice boards, libraries, GP surgeries, leisure centres, local town centres and local radio. Existing services should publicise details of other services on their premises.

Not all professionals were aware of all local services, or the facilities each local service provides. Information about any changes in local services needs to be sent to each professional working for each organisation, rather than being sent to one individual for dissemination.

A program of outreach work in schools and youth clubs should be developed. Visits to the FPC by young people from local schools and youth clubs should be arranged.

\section{Encouraging use by young men}

To increase use by young men it was suggested to either have a non-health based service such as an information and advice 'shop', or to have 'men only' sessions in existing clinics with appropriate opening hours and staffed by men.

\section{Encouraging use by disabled}

The FPC has wheelchair access. A team specialist may be useful to meet disabled people in the community, then arrange group visits to the service.

\section{Encouraging use by ethnic minorities}

Staveley has a very small ethnic population. Pictures on health promotional material should include people from ethnic minorities in addition to the disabled and sexual minorities.

\section{Sex and relationships education}

This should be started at an earlier age and should include more work on STIs, safer sex, assertiveness skills and the discussion and challenge of gender and cultural stereotypes. Staff should have an interest and receive training in the necessary information and skills.

\section{Discussion}

The needs of young people in other populations have been identified. ${ }^{5,6,7}$ It is reassuring that this study has results in common with these studies. However, it is important to identify local circumstances and needs when considering a change to service provision ${ }^{8}$ and this project has identified useful local information.

It is important that a choice of local services be maintained in line with government policy, ${ }^{9}$ other local research ${ }^{10}$ and young people's personal preferences, in order to achieve the maximum possible uptake of services.

Less young men than women participated in this study. Literature review identified other ways of promoting services for this hard-to-reach group that may be more feasible in a small area. These include taking services to places where men gather, getting involved in school sex education to teach about sexual health and using services, establishing links with agencies that men use, and publicising to men the relevance of available services. ${ }^{11}$

Clinic-based services have been shown to be associated with reduced conception rates in teenagers. ${ }^{12}$ Staveley clinic staff have met and agreed an action plan to implement user-friendly changes to our service. We met with local professionals to share and discuss the findings, publicise the changes to our clinic and identify potential interest in a more holistic service. A leaflet with details of all local services has been distributed to schools, youth clubs and GP surgeries. Our outreach and liaison nurse has helped with the sex education programme in the local secondary school. Visits to the clinic by young people have been offered.

Attendances are slowly increasing. An evaluation of the changes to date is planned for autumn 2000.

\section{Acknowledgements}

Thank you to the young people and professionals who participated in the study, to Sue Carrot, Lyndsay Sands, Dr H King, Dr ES Searle, and to staff from the following organisations: Community Health Care Service (North Derbyshire) NHS trust, Derbyshire Youth and Community Service, Derbyshire Education Service, North Derbyshire Health, Chesterfield and North Derbyshire Royal Hospital NHS Trust, Sheffield Centre for Health and Related Research, CASH project.

\section{Statements on funding and competing interests}

Funding. North Derbyshire Community Family Planning Service kindly supplied funding for focus group assistant, stationery and postage. Competing interests. None declared.

\section{Further information}

This paper is a short summary of the full project. For further information, a copy of the executive summary or project: Young People's Contraception and Sexual Health In Staveley, North Derbyshire: Shaping a Community Service Appropriate to Local Needs, please contact the author

\footnotetext{
References

Measuring the effectiveness of contraceptive services. Guidelines for health promotion Number 37. London: Faculty of Public Health Medicine, August 199

Jones A, Harris J. Evaluating the effectiveness of contraception services for teenagers. Audit methodologies. Hull: National Co-ordinating Unit for Clinical Audit in Family Planning, July

Harris J, Sellers T, Westerby M. Developing a whole - community approach to teenage sexual health. University of Hull: Department of Public Health and Primary Care, November 1997.
} 
4 Ingham R. Promoting sexual health services to young people. Guidelines for purchasers and providers. London: Health Education Authority, 1996.

Allen I. Family planning and pregnancy counselling projects for young people. London:

Wilson SH, Denman S, Gillies PA, et al. Purchasing services to promote the sexual health of young Jones $\mathrm{M}$. Clients express preference for 92(2): $32-33$

University of York: NHS Centre for reviews and Dissemination. Preventing and reducing the adverse effects of unintended teenage pregnancies. Effective Health Care 1997; 3(1).
9 Family Planning Services: A model for district health authorities. London: Family Planning

Association, 1990.
Singleton C, Reuter S. Dual provision or duplication? A survey of family planning provision

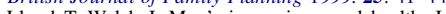

Cater Y, Moss C, Weyman A. RCGP

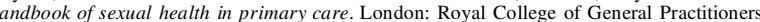

12 Allaby MA. Contraceptive services for teenagers: do we need family planning clinics? British Medical Journal 1995; 310: 1641-643. 